\title{
Assisted Breech Delivery
}

National Cancer Institute

\section{Source}

National Cancer Institute. Assisted Breech Delivery. NCI Thesaurus. Code C114137.

The birth of a breech-presenting fetus with operative instrumentation or assistance. 